\title{
FUNDAMENTAL INFLUENCERS RELATED TO LANGUAGE-BASED DIFFICULTIES IN FINANCIAL MATHEMATICS
}

\author{
A. Bayaga \\ Department of Senior Secondary Education \\ Nelson Mandela University \\ Port Elizabeth, South Africa \\ e-mail: Anass.Bayaga@mandela.ac.za / https://orcid.org/0000-0003-0283-0262
}

\section{Khalo}

School of Further and Continuing Education, Faculty of Education

University of Fort Hare

East London, South Africa

e-mail: xkhalo@ufh.ac.za

\section{G. Moyo}

Department of Social science

University of Zululand

Richards Bay, South Africa

e-mail: Moyog@unizulu.ac.za

\section{ABSTRACT}

Motivated in part by a sustained amount of research in South Africa and principally guided by techniques of problem-solving suggested by Polya as well as error analysis by Newman, the current research examines fundamental influencers (underlying factors) relating errors due to language difficulties in financial mathematics concerning the language of instruction. The current research was accomplished using a case study design. The sample size was 105 out of a population of 186, with assumption of confidence and precision levels at 95 per cent and 0.5 respectively. The aim of the study was addressed by using both sets of structured-interview and document analysis for collecting data. Analysis of data was conducted by both content analysis as well as correlation analysis, wherein, the analysis revealed that errors committed by learners in financial mathematics were due to language difficulties. In contrast, misinterpretation of the mathematical semantics was not as a result of not indicating answers as expected, not following instructions, and not understanding instructions.

Keywords: errors, financial mathematics, language difficulty

\section{INTRODUCTION}

The current research examines the fundamental influencers (underlying factors) relating errors due to language difficulties in financial mathematics concerning the language of instruction. 
The present study is important in South Africa due to the continued attention language-based errors have received (Van Jaarsveld 2016). Others (e.g., Mercer and Sams 2006; Schütz 2002; Skemp 2006; Uys et al. 2007) tend to report on similar issues. For instance, Van Jaarsveld (2016, 150-166) examined “... language as an aspect of rigour in initial teacher education mathematics programmes". Previously, Mercer and Sams (2006, 507-528) examined "teaching children how to use language to solve maths problems". Others examined the effect of language acquisition (English as a channel of teaching) in terms of relational and instrumental instructions and Vygotsky discourse in mathematics cognition (e.g., Schütz 2002; Skemp 2006; Uys et al. 2007). Additionally, South Africa's Department of Basic Education (DBE 2014, 116) highlights that "as language presents problems in the correct interpretation of (finance) questions, teachers must at all times focus on using the correct language, while teaching and in the setting of assessment tasks".

There are a number of issues associated with both DBE (2014) and some of the studies previously mentioned. For instance; (1) guided by the language approaches or modalities such as Vygotskian thought and language. Another being; (2) the Freirian emancipatory critical consciousness and the last (3) being Habermasian ethical and moral communicative action, Van Jaarsveld (2016, 152) partly agrees with DBE (2014). While, the agreement is by acknowledging "the need to use correct or exact mathematical language for mathematics teaching and learning ...", but what is lamenting is that "... what constitutes the correct use of mathematical language, is not addressed" when one considers the three points (Van Jaarsveld 2016, 152). Although the frameworks of Vygotski, Freirian, and Habermas frameworks, are beyond the scope of this current study, readers are encouraged to consider Van Jaarsveld (2016) for a detailed analysis.

While connections between mathematics and language learning have a history of study, the research is sparse in the context of financial mathematics and accounting, regarding precise aspects of mathematical language (Van Jaarsveld 2016). Those who have investigated connections between mathematics and learning have frequently addressed the model method and its effectiveness in respect to students' performance (Ho and Lowrie 2014). For instance, Aygor and Ozdag (2012) focussed on misconceptions in linear algebra; Columba (2012) examined how sorting mathematical representations affects cognition; others have investigated teacher knowledge of students' mathematical errors (e.g., Peng 2009); and Sakpakornkan and Harries (2003) examined the relationship between learners' processes of cognition and how to answer algebraic tasks in United Kingdom and Asia.

Extending on the works of those previously cited, a growing trend in South Africa has been to examine mathematical thinking and factors related to errors due to language difficulties 
particularly on differentiating concepts of finance (e.g., cost price, selling price, profit, and loss) which are fundamental, yet not satisfactorily addressed in financial mathematics (Brodie 2014; Brodie and Shalem 2011; Gardee and Brodie 2015; Hansen 2011; Ingram, Baldry, and Pitt 2013). While not precisely in the genre of financial mathematics, Gardee and Brodie $(2015,2)$ recommended that there is the need for teachers to use "... their professional knowledge to decide when, why and how it is appropriate to correct, probe or embrace errors in light of their knowledge of the content and their learners".

In related investigations, Brodie (2014) examined the nature of learner errors, Brodie and Shalem (2011) analysed accountability conversations in mathematics, Hansen (2011) interrogated common misconceptions in the primary schools and Ingram et al. (2013) examined the correlates of interactionally managing mathematical mistakes and mathematics cognition.

Contrasting the vast array of both local works (e.g., Brodie 2014; Brodie and Shalem 2011; Gardee and Brodie 2015; Hansen 2011; Ingram et al. 2013) and international studies (e.g., Aygor and Ozdag 2012; Columba 2012; Ho and Lowrie 2014; Peng 2009) with the lack thereof regarding fundamental influencers relating errors due to language difficulties in context of financial mathematics, the current research examines errors and misconceptions students encounter related to learning financial mathematics as well as seeks to comprehend why learners carry on to make those errors; understanding such could lead to developing mechanisms to avoid such errors.

\section{RELATED WORK}

\section{Financial mathematics cognition and conceptualisation}

For decades, research has investigated methods or modalities involved in solving problems. Early on, Polya (1957) developed a four-step heuristic for solving problem (i.e., comprehending the task, devise a strategy, execute the strategy, and check the answers). Various studies have attempted to examine: students' mathematical errors (Peng 2009); reasoning about learners' mathematical thinking (Sheinuk 2010); deepening mathematical knowledge (Watson 2010); using cognitive situative perspective to comprehend instructor's interactions with learners (Brodie 2005), and how to sort mathematical representations via words, symbols, and graphs Columba (2012). Additional research has emphasized numeracy, literacy, and error analysis (White 2010). For instance, White (2010) examined the relationship between numeracy/literacy as well as Newman's error techniques.

During the search for modalities or approaches in comprehending fundamental influencers for learners making errors and discovering the appropriate approaches to avoid them, White 
(2010), directed by Newman's error analysis (NEA), suggested NEA could be a better analytic tool for examining errors committed by learners. This is because, Newman's error techniques as well as follow-up plans could help learners with their problem-solving technique, thus allowing teachers to develop a much more consistent approach to the teaching of problemsolving. White (2010) highlighted views of the language demand of problem-solving and demonstrated that via a systemic approach, instructors could concentrate upon teaching for more in-depth comprehension.

A general assessment of the work of Sheinuk (2010), Columba (2012) and Peng (2009) suggest that learners carry on to make errors in financial mathematics problems. As research has considered how learners struggle to demonstrate competence in various topics (Ho and Lowrie 2014; Ingram et al. 2013), some have articulated reasons for such (e.g., Ay 2017; Brodie 2014; Ingram et al. 2013. For instance, some have considered underlying factors related to language-based difficulties (Brodie 2014; Brodie and Shalem 2011; Duran 2013; Durkin and Rittle-Johnson 2015).

Based on the work of Hadjidemetriou and Williams (2002), Aygor and Ozdag (2012, 2989) distinguished between an “... error (i.e., erroneous responses to a question) ...” as well as “... misconception, which may be part of a faulty cognitive structure that causes, lies behind, explains or justifies the error," and suggested that the two may be attributable to student difficulty in financial mathematics. Distinguishing errors from misconceptions, Aygor and Ozdag $(2012,2989)$ cautioned that "some errors may be symptomatic of a misconception ..." meaning "... a prototypical way of thinking, or an intuition," while others "... may not. They may simply be the result of faulty memory, cognitive overload ...”. They further suggest that “... misconceptions [for instance] may sometimes be more than simply a justification for an error”. Predicated on studies by Leinhardt, Zaslavsky, and Stein (1990), Aygor and Ozdag (2012, 2989) concluded that,

'there can be the general features of students' mathematics learning, such as students' tendency to over-generalise a correct conception or to be influenced by interference from common knowledge and experience. They lead pupils to construct some well-formulated alternative frameworks of ideas which are not appropriate."

Others have concluded that "errors might be the results of (i) interference from new learning; (ii) difficulty in operating with the negative integers; (iii) misconceptions of algebraic expressions; and (iv) misapplication of rules" (Seng 2012, 139-162). To that effect, Columba $(2012,3)$ concluded that, 
"words, symbols, and graphs are powerful methods of communicating mathematical ideas and relationships. These tools allow students to express mathematical ideas to people. Moving from one representation to another is an important way to enhance mathematical concepts."

While the majority of research connecting language to mathematics learning seems to be contextualized in the difficulties students encounter in solving linear equations (e.g., Sakpakornkan and Harries 2003), comparatively few studies have addressed financial mathematics (e.g., Ay 2017; Almog and Ilany 2012; Dobbins, Gagnon, and Ulrich 2014; Duran 2013; Durkin and Rittle-Johnson 2015; Keçeli and Turanlı 2013; Koklu and Topcu 2012; Kula and Bukova Güzel 2014; Lin, Ko, and Kuo 2014; Lin, Yang, and Li 2015; Ojose 2015; Yang and Lin 2015). Synthesizing the previously mentioned research literature, two main challenges have been recognized - and can be particularized to the content of financial mathematics: (1) the need to identify the underlying factors related to learners' language-based difficulties in mathematics and (2) the need to comprehend the reasons why learners carry on to make such errors, such that approaches to circumvent such can be developed. Altogether, these challenges warrant the current research and objectives.

\section{RESEARCH OBJECTIVES AND HYPOTHESIS}

Several modalities have been considered in examining factors relating language-based difficulties in mathematics learning (e.g., Aygor and Ozdag 2012; Ayres 2000; Brodie 2005; Murray 2012; Peng 2009; Seng 2012; White 2010). For example, Aygor and Ozdag (2012) examined undergraduate students' misconceptions in linear algebra. Brodie (2005) and Peng (2009) suggested that emphasis should be on establishing cognitive situatedness in conjunction with teacher knowledge and learner error. Murray (2012) believed that challenges with word problems should be the emphasis in mathematics teaching and learning. White (2010) drew upon Newman's error analysis in examining numerical cognition and analysing student errors. From a different perspective, Ayres (2000) focussed on mental prowess as a tool to understand mathematical errors.

Unfortunately, there yet remain gaps in fully understanding factors related to languagebased mathematical difficulties. In part, this may be because, for those who base their investigations on misconceptions demonstrated by students, there are opposing studies that have revealed that mathematical cognition correlates; non-verbal spatial consideration of quantity as well as verbal comprehension related to language and symbolic cognition (Murray 2012). Thus, the explanation of mathematical cognition may closely be associated with language learning processes. That is, Murray $(2012,49)$ suggests that the foremost part of developing knowledge of mathematics (and, thus, financial mathematics) involves learning to 
interpret and use a set of mathematics language patterns "... symbols and vocabulary in order to make connections between them". This, in part, implies that in order for students to demonstrate competence in financial mathematics, they must understand and utilize its unique language.

Altogether, connecting previously cited research and the works of Murray (2012) and Polya (1957), several propositions regarding language-based mathematical difficulties could be reached and thus re-examined. One such proposition is that learners' capability to comprehend the language of teaching together with their degree of reading plays an integral role in effective learning. It is also fair to claim that, in word problem-solving, learners ought to be familiarised with the language used and the mathematical ideas, notations, and terminology.

Mathematical learning may be additionally complex in countries such as South Africa, where English is both a second language and the language of instruction (Baldwin and Yun 2012). In these situations, misunderstanding the semantics of the mathematical notation may result in one of the sources of learners' difficulties. Thus, some may perceive the learning of mathematical concepts, symbols, and vocabulary as an additional layer of a foreign language. Recognizing the complexity of language learning in mathematics, Baldwin and Yun (2012) state that, in solving word problems, learners must distinguish between the mathematical meaning of words and the word's meaning in natural language. Consequently, poor language abilities, involving the need to read, how to write as well as speak are linked with poor achievement in mathematics.

Arguably, all these factors above pose a challenge to learners of financial mathematics as they struggle to grasp some of the terminology associated with financial mathematics. This is particularly the case when the language of instruction is already a second language. Altogether, while "learners may lack reading comprehension skills that are required to interpret the information needed to solve a problem” they “... may also have difficulty in understanding academic language required to solve a problem" (Baldwin and Yun 2012, 25).

\section{Research objectives}

Connecting to the cited related work, the research objectives of this current study were aimed at; (1) identifying language-based financial mathematical difficulties committed by learners (2) understanding the reasons learners carry on to commit those errors such that mechanisms can be developed to circumvent such errors in the future.

\section{Hypothesis}

Without loss of generality, we selected the hypothesis that errors committed by learners are not 
impacted upon by neither the misunderstanding of the semantics of mathematical text nor the language of instruction in financial mathematics.

\section{Research methodology}

A positivist paradigm directed by quantitative approach was applicable to establish causes and effects of data from 105 interviewees via a simple random technique. The 105 interviewees were GR10 mathematical literacy (ML) learners, chosen conveniently from a secondary school from East London in Eastern Cape, South Africa. The school had five GR 10 ML classes; thus, population (N) was equal to 186 . Guided by formula by Israel (2009), the sample size (n) was estimated as 105, given levels of precision $(e)$ and confidence level $=0.5$ and 95 per cent respectively: That is $\mathrm{n}=\mathrm{N} / 1+\mathrm{N}(\mathrm{e})^{2}=105$.

Two data sets were collected. First was structured-interview. The second was document analysis of examiners reports. The document analysis was based on (1) the underlying reasons for learners to make errors based on a task in financial mathematics, and (2) errors due to perceived language difficulties. The first set was used for a content-based instrument wherein interviewees were asked to work out financial mathematics tasks (directed by Newman's error technique in content analysis and identification of errors made) as well as another including the likely fundamental influencers relating forms of errors learners made (a Likert scale questionnaire).

The content-based questionnaire asked participants to provide responses to the three research questions below.

Question 1. For each of the blanks, describe the scenario being presented with two choices from the list of: high priority, low priority, variable, static, regular, occasional.

(a) Mandisa has to pay Instant Pool for installing a swimming pool at her home. and

(b) Normandla has to go to the vet for treating her dog when it was ill. and

(c) Chris buys an old plough from a farmer to display in his garden. and

(d) Sipha has to pay the monthly fee for his daughters' attendance at nursey school. and

(e) Mondli has to pay his cell phone bill. and 
Question 2. Complete the table with values/labels.

\begin{tabular}{|l|c|c|c|c|}
\hline \multicolumn{1}{|c|}{ Item } & Cost price & Selling price & Profit/Loss & $\begin{array}{c}\text { Amount of } \\
\text { profit/loss }\end{array}$ \\
\hline Leather Lounge Suite & R9 999,95 & R8 000,00 & & \\
\hline Bedroom Suite & R4 999,95 & R4 375,00 & & \\
\hline Home Theatre System & R1 199,95 & & Profit & R200,05 \\
\hline Dining Room Suite & & R6 500,00 & Loss & R2 499,95 \\
\hline Wall Unit & & R3 550,00 & Profit & R350,00 \\
\hline
\end{tabular}

Question 3. Consider the entire table and determine if the complete table demonstrates a profit or loss and how much of profit or loss resulted.

Correlation analysis was used to establish the relationship among variables such as: I don't indicate answers as expected, I don't follow instructions, I don't understand instructions, and I write any answer in the language of instruction in financial mathematics. Participants were assured of privacy, confidentiality, and anonymity of any identifying data.

\section{RESULTS}

Learner 16 (see Figure 1) was among the 37 learners (35\%) who answered Question 1 correctly. Most learners could not associate the words high priority, low priority, variable, static, regular, or occasional to the scenarios presented. Errors committed in this question were attributed to language difficulties.

Question 1. For each of the blanks, describe the scenario being presented with two choices from the list of: high priority, low priority, variable, static, regular, occasional.

(a) Mandisa has to pay Instant Pool for installing a swimming pool at her home.

(b) Normandla has to go to the vet for treating her dog when it was ill.

(c) Chris buys an old plough from a farmer to display in his garden.

(d) Sipha has to pay the monthly fee for his daughters attendance at nursey school.

(d) Sipha has to pay the monthly fee for his daughters attendance at nursey school.

(e) Mondli haș to pay his cell phone bill. Variable and

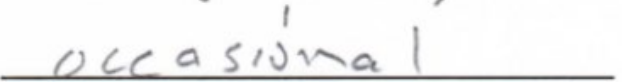

Figure 1: Response of Learner 16 to Question 1.

For Question 2, respondents were expected to differentiate the following concepts: cost price, selling price, profit and loss. If learners understood the meaning of those concepts they would then be able to calculate the amount of profit as well as of loss when given the cost price and 
selling price. In this question, respondents demonstrated errors due to incorrect association or stringency of cognition as well as errors due to language difficulties. As previously proposed, learners often lack the understanding of concepts (e.g., cost price, selling price, profit, and loss) as well as the interrelationship between the concepts and the basic operations to employ when performing the mathematics connected to each of the concepts. Most learners answered Question 2 incorrectly ( $\mathrm{N}=68$ or $65 \%$ ), because they could not establish the relationship between the concept and the relevant algorithms to employ to arrive at the correct answer. Learner 11 (see Figure 2) was one of the learners who identified profit as a result of adding the cost price and the selling price.

Question 2. Complete the table with values/labels.

\begin{tabular}{|c|c|c|c|c|}
\hline Item & Cost price & Selling price & Profit/Loss & $\begin{array}{l}\text { Amount of } \\
\text { profit/loss }\end{array}$ \\
\hline $\begin{array}{l}\text { Leather Lounge } \\
\text { Suite }\end{array}$ & R9 999,95 & R8 000,00 & 17 & 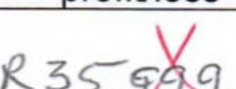 \\
\hline Bedroom Suite & R4 999,95 & R4 375,00 & & \\
\hline $\begin{array}{l}\text { Home Theatre } \\
\text { System }\end{array}$ & R1 199,95 & 18400.00 & & R200,05 \\
\hline $\begin{array}{l}\text { Dining Room } \\
\text { Suite }\end{array}$ & R8.9994 & R6 500,00 & Loss & R2 499,95 \\
\hline Wall Unit & 23,9000 & R3 550,00 & Profit & R350,00 \\
\hline
\end{tabular}

Figure 2: Response of Learner 11 to Question 2.

In Question 3, respondents were expected to state whether the table, taken as a whole, demonstrated a profit or loss and of how much. Learners could check the table to find the number of items on which profit/loss was made. They could add the amounts of profit and also add the amounts of loss and compare them. If the sum of amounts of profits was greater than the sum of losses, they could conclusively state that a profit was made. Only 38 per cent of the learners answered Question 3 correctly. Through later conversations with the researchers, incorrect responses were attributed to either an error due to language difficulties (learners could not state whether profit/loss was made because they were unsure of the meaning of each) or a rigidity of thinking (considering each line in the table, but not the whole). For instance, Learner 31 (See figure 3) only attempted to calculate the values recognized as profits. Figure 4 depicts the work of Learner 52, who considered both profits and losses, but does not combine the two to determine the result of the entire table. 


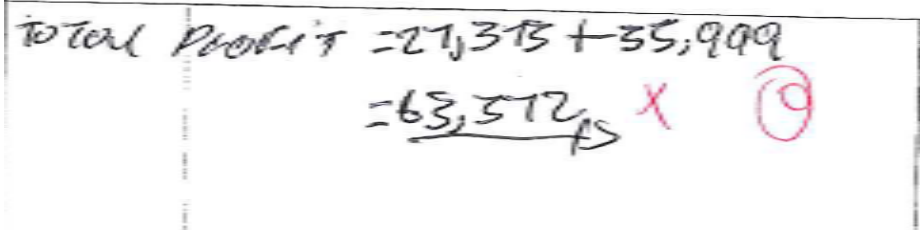

Figure 3: Response of Learner 31 to Question 3.

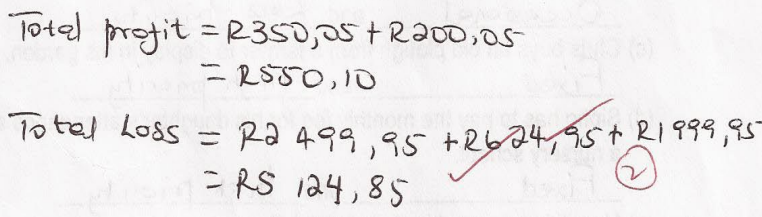

Figure 4: Response of Learner 52 to Question 3.

After the students completed their tasks, using four predefined options, they were requested to self-report on their cognition although answering the questions. These options included:

(A) I don't indicate answers as expected. Of the participants, 40.9 per cent reported that they failed to provide expected answers, with 35.2 per cent reporting that they occasionally committed such and 5.7 per cent reported that they always committed such an error on these research questions.

(B) I don't follow instructions. About 34.3 per cent reported that, although they read the instructions, they did not follow.

(C) I don't understand instructions. About 61 per cent of the respondents reported that they did not understand the instructions of a given task, while 58.1 per cent claimed to experience such occasionally.

(D) I write any answer. Approximately, 61 per cent of the students reported that they simply wrote any answer, when they could not understand what was asked; while 12.4 per cent reportedly did this always, 48.6 per cent claimed to occasionally do so

Table 1 provides a summary of the results of correlation analysis and the significance of the 4 influencers tested of the fundamental influencers to the errors due to language difficulties. In examining the relationship between learners who do not follow instructions (B) and learners who do not understand instructions $(\mathrm{C})$, a non-significant result $(p=.832)$ and a weak negative correlation ( $r=-.02$ ) was revealed. The relationship between learners not following instructions (B) and learners writing any answer (D) revealed non-significant results $(p=.503)$ and a weak negative correlation $(r=-.09)$. The correlation analysis between learners not understanding instructions (C) and learners not following instructions (B) was not significant, $p=.473$ and $r$ $=+.15$. The relationship between learners not following instructions (B) and learners writing 
any answer (D) revealed no significance, as $p=.884$ and $r=-.04$. The relationship between learners who do not understand instructions (C) and learners who write any answer (D) revealed no significance, as $p=.473$ and $r=+.06$. In the following discussion section, we will address the meaning of these measures of minimal correlation among some of the variables.

Table 1: Correlation analysis: Influencers relating errors due to language difficulties

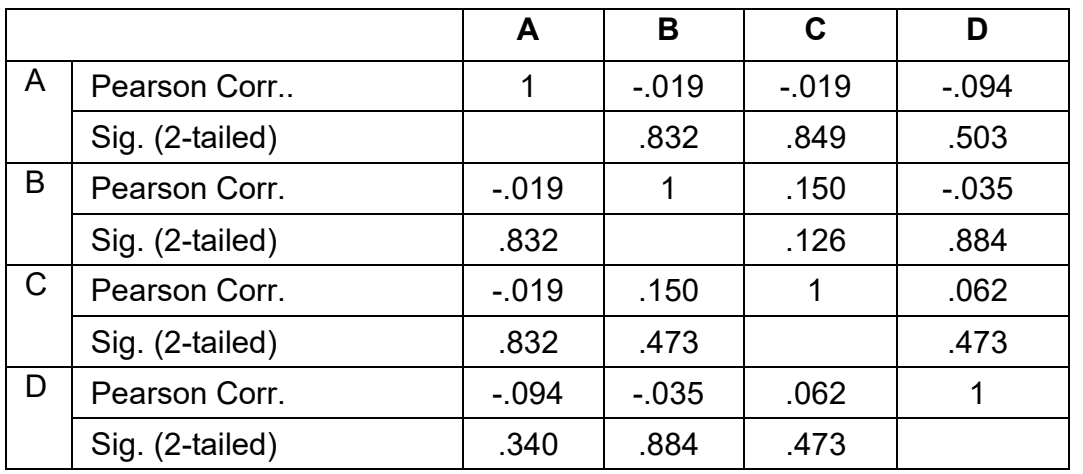

\section{DISCUSSIONS}

From the four pairs of influencers of the fundamental variables related to language-based errors, none of them illustrated any correlation between the language of instruction and the understanding of financial mathematics. Thus, the variables had no significant effect on the instruction in financial mathematics. Notably, the results may be inconsistent with the generally accepted view of specific errors and miscomputations caused by not indicating answers as expected, not following instructions, not understanding instructions in the instruction of mathematics finance as suggested by Ay (2017). Ay's analysis of misconceptions in mathematics suggested that most of the research involved primary and high school learners and that "... most of the studies were conducted for the purpose of determining misconceptions, not eliminating misconceptions" $(2017,21)$. This observation is vital because, students' perceptions, beliefs, and thoughts are inextricably interconnected with their mathematical thinking and that any of these dimensions may blur mathematical conceptualisation. In fact, to this effect, it was argued that "... people cannot distinguish the misconception and error" because "... misconceptions are the subset of errors, which means one can define all misconceptions as errors but all errors may not be misconception" $(2017,21)$. This may all imply that an error in financial mathematics ".. is the result of misconception, or a type of perception which systematically produces error", and thus "... it is more important that teachers ... focus on misconceptions, which are the source of errors" $(217,21)$.

In the analysis of the student work in this study, the following errors were identified. Learners did not comprehend the meaning of some mathematical terminology (e.g., loss, profit, cost price) and employed incorrect algebraic strategies leading to incorrect answers. This 
challenge associated with lack of comprehension of concepts may be connected to other sources of errors apart from simply linguistic misapprehensions (Almog and Ilany 2012; Dobbins et al. 2014; Durkin and Rittle-Johnson 2015; Kula and Bukova Güzel 2014; Lin et al. 2014; Lin et al. 2015; Luneta and Makonye 2010). To this end, while Luneta and Makonye (2010) suggested further need to examine South African learners' errors and misconceptions in Grade 12 elementary analysis classes, Almog and Ilany (2012) explored high school learners' answers and misconceptions in the context of absolute value inequalities. Thus, the recognition of the need to investigate students' misconceptions continually advances the need for research.

The data in this study may indicate that the students' wrestlings with the language of instruction does not necessarily statistically correlate to their struggles with the mathematical content. In part, this may be because mathematics has some aspects of a universal language transcending particularities of verbal languages. However, the participants of this study, while demonstrating that they did not all understand the instructions involved in the problems, demonstrated mathematical misconceptions which were not correlated to their linguistic challenges in the language of instruction. While this may be interesting, it begs the question as to what it all means. Indeed, we must first be cautious. While the study shows no correlation between student perceived struggles with language and learning, we cannot state categorically that student self-reported opinions validly depicted actual struggles with the language of instruction.

Notably, there seems to be some inconsistency between student opinions and student mathematical results. It would seem that a number of students associated their mathematical struggles with their struggles to understand the questions in the language of instruction. However, the statistical analysis may belie this opinion. Therefore, while beyond the scope of this investigation, it must be wondered if students attempted to use actual or perceived language barriers as an excuse for poor mathematical understanding and performance. Notably, this study was performed in a region of South Africa in which many of the students had a native language other than that of English, the language of instruction. However, even with this in mind, these students had received mathematics instruction in English for most of their academic careers. This may lead to the need for additional research regarding students' attitudes and beliefs regarding mathematics learning and the language of instruction. However, there is the possibility that, rather than the perceived and self-reported difficulties some students claimed regarding struggling with the language of instruction, some students actually struggled with the English language instructions and questions. This possibility, however, was not the purpose for this study.

Since the statistical analysis demonstrated no significant correlation between students 
correctly performing the mathematics and the language of instruction, it is hypothesized that the mathematically successful students were able to decontextualize the mathematics from the language through which it was presented. This agree with a number of studies (e.g., Almog and Ilany 2012; Dobbins et al. 2014; Durkin and Rittle-Johnson 2015; Kula and Bukova Güzel 2014; Lin et al. 2014; Lin et al. 2015; Luneta and Makonye 2010), which have concluded that, to arrive at the accurate final answer in financial mathematics, word-problems need to be decontextualized from the language through which it is presented. This is consistent with the findings of Van Jaarsveld (2016) who realized that, in the context of investigating the interplay of language and mathematics, many South African [initial mathematics teacher education (preservice)] candidates struggled with concepts and required investigations leading to deeper conceptual understanding. This may have two interconnected implications. First, native language and the language of instruction may interact in some manner and present a barrier to mathematical understanding and arriving at correct answers. Second, these language-based impediments can be overcome. The position held by this current research's findings highlights Van Jaarsveld's $(2016$, 153) view that "English has become, irrespective of the merits or demerits of the matter, the dominant medium of instruction in southern Africa ..." and that "... one needs to be cognizant of its implications for subject teaching". In a parallel discussion regarding the South African students' education and learning environment, it was stated that, due to "poor language ability, the majority of learners did not provide good answers to contextual questions ... thus they could not identify the mathematical skills involved" (DBE 2011, 99).

Despite student recognized struggles with the questions and directions in the language of instruction, the data and some respondents attributed some of the challenges they experienced to struggles specifically regarding understanding and correctly performing the algebraic operations connected with financial mathematics. This result is consistent Healy and Hoyles (2000), Lamport (2012), and Pfeiffer $(2010,21)$ who established the need for "the role of proof validation in students' mathematical learning". For instance, in a study regarding algebraic proofs, Demby (1997) and Healy and Hoyles (2000) highlighted the need for accurate conceptual understanding as it affects other fields of study such as financial mathematics. Grounded upon this, Lamport (2012) urged the need for students to understand how to write algebraic proof due to the general effects it has on other courses and the fact;

“... there is a deeper language issue here, a case in which ... the injudicious use of mathematical language in classrooms makes explaining the content and elaborating its meaning for learners incomprehensible and inaccessible especially where English is already not the mother tongue of the majority of learners" Van Jaarsveld $(2016,153)$.

In financial mathematics Van Jaarsveld $(2016,153)$ laments that "equations, for instance are 
often referred to as 'expressions' and vice versa, 'positive' is used as a synonym to describe a function that is 'increasing' even when such a function is both positive and negative". More strangely, “... the instructional verb 'solve' is applied generically to mathematical objects even where the objects may need to be 'simplified' or 'sketched'." Thus, through the lens of Van Jaarsveld (2016), White (2010) suggests that Newman's error analysis (NEA) could be applied by educators to include error analysis in their lesson plans. Information of why learners make errors is treasured to instructors since it may assist with eliminating different types of errors. Error analysis is important as suggested by Ay (2017) because, errors in mathematics education has become pervasive, wherein Türkdoğan et al. (2015) and Yang and Lin (2015) emphasised the need for such studies in Turkey and that performance and misconceptions could be affected regardless of age.

\section{CONCLUDING REMARKS}

Conclusively, while the current research supports previous work on the association of language difficulties and error analysis, in part, the results contradicted the notion that semantics of mathematical text was as a result of reasons such as not indicating answers as expected, not following instructions, not understanding instructions. Thus, similar to what was revealed in the introductory section of the current study, in South Africa, there is a continues attention or drive of research towards language as a source of difficulty or errors. This view is similar in financial mathematics in the mathematical literacy class. However, misunderstanding of the semantics of mathematical text could not be fully established, taking into account not following instructions and not understanding instructions which could serve as a future point of research. Thus, based on the hypothesis, the variables had no significant effect on the instructions in financial mathematics.

\section{REFERENCES}

Almog, N. and B. Ilany. 2012. "Absolute value inequalities: High school students' solutions and misconceptions." Educational Studies in Mathematics 81(3): 347-364.

Ay, Y. 2017. "A review of research on the misconceptions in mathematics education." Education Research Highlights in Mathematics, Science and Technology: 1-12.

Aygor, N. and H. Ozdag. 2012. "Misconceptions in linear algebra: The case of undergraduate students." Procedia - Social and Behavioral Sciences 46, 2989-2994.

Ayres, P. 2000. "Mental effort and errors in bracket expansion tasks." In Mathematics education beyond 2000, ed. J. Bana and A. Chapman, 80-86.

Baldwin, E. E. and J. T. Yun. 2012. "Mathematics curricula and formative assessments: Toward an error-based approach to formative data use in mathematics." Santa Barbara, CA: University of California Educational Evaluation Center. https://ucec.gseis.ucla.edu/Baldwin_Yun_2012.pdf.

Brodie, K. 2005. Using cognitive situative perspective to understand teacher interaction with learner error. Proceedings of the $29^{\text {th }}$ Conference of the International Group for the Psychology of Mathematics Education 2: 177-184. 
Brodie, K. 2014. "Learning about learner errors in professional learning communities." Educational Studies in Mathematics 85: 221-239.

Brodie, K. and Y. Shalem. 2011. Accountability conversations: Mathematics teachers' learning through challenge and solidarity. Journal of Mathematics Teacher Education 14(6): 419-439.

Columba, L. 2012. "Sorting Mathematical Representations: Words, Symbols, and Graphs." Learning \& Teaching 12: 3-8.

DBE see Department of Basic Education.

Demby, A. 1997. "Algebraic procedures used by 13-to-15-year-olds." Educational Studies in Mathematics 33: 45-70.

Department of Basic Education. 2011. Curriculum and Assessment Policy Statement Grades 10 - 12 Mathematics. http://www.education.gov.za (Accessed 23 January 2019).

Department of Basic Education. 2014. National Senior Certificate Examination National Diagnostic Report, 12. http://www.education.gov.za (Accessed 10 January 2019).

Dobbins, A., J. C. Gagnon, and T. Ulrich. 2014. "Teaching geometry to students with math difficulties using graduated and peer-mediated instruction in a response-to-intervention model." Preventing School Failure 58(1): 17-25.

Duran, M. 2013. "Opinions of primary 7th-grade students about visual mathematics literacy." Mehmet Akif Ersoy University Journal of Educational Sciences Institute 2(2): 38-51.

Durkin, K. and B. Rittle-Johnson. 2015. "Diagnosing misconceptions: Revealing changing decimal fraction knowledge." Learning and Instruction 37(2015): 21-29.

Gardee, A. and K. Brodie. 2015. "A teacher's engagement with learner errors in her Grade 9 mathematics classroom." Pythagoras 36(2), Art. 293, 9 pages. https://doi.org/ 10.4102 /pythagoras.v36i2.293.

Hadjidemetriou, C. and J. S. Williams. 2002. "Children's graphical conceptions." Research in Mathematics Education 4: 69-87.

Hansen, A. 2011. Children's errors in mathematics: Understanding common misconceptions in primary school. $2^{\text {nd }}$ Edition. Exeter: Learning Matters Ltd.

Healy, L. and C. Hoyles. 2000. "A study of proof conceptions in algebra." Journal for Research in Mathematics Education 31(4): 396-428.

Ho, S. Y. and T. Lowrie. 2014. The model method: Students' performance and its effectiveness. The Journal of Mathematical Behavior 35: 87-100.

Ingram, J., F. Baldry, and A. Pitt. 2013. "The influence of how teachers interactionally manage mathematical mistakes on the mathematics that students experience." In Proceedings of the 8th Congress of the European Society of Research in Mathematics Education, ed. B. Ubuz, Ç. Haser, and M. Mariotti, 1487-1495. Ankara: European Society of Research in Mathematics Education. http://cerme8.metu.edu.tr/wgpapers/WG9/WG9_Ingram.pdf.

Israel, G. D. 2009. Determining the sample size. Program Evaluation and Organisational Development. IFAS, University of Florida. PEOD-6.

Keçeli, V. and N. Turanl1. 2013. "Misconceptions and common errors in complex numbers." Hacettepe University Journal of Education 28(1): 223-234.

Koklu, O. and A. Topcu. 2012. "Effect of Cabri-assisted instruction on secondary school students' misconceptions about graphs of quadratic functions." International Journal of Mathematical Education in Science and Technology 43(8): 999-1011.

Kula, S. and E. Bukova Güzel. 2014. "Misconceptions are emerging in mathematics student teachers' limit instruction and their reflections." Quality \& Quantity 48: 3355-3372.

Leinhardt, G., O. Zaslavsky, and M. K. Stein. 1990. "Functions, graphs, and graphing: Tasks, learning, and teaching." Review of Educational Research 60(1).

Lamport, L. 2012. "How to write a 21st-century proof." Journal of Fixed Point Theory and Applications 
11: 43-63.

Luneta, K. and P. J. Makonye. 2010. "Learners' errors and misconceptions in lementary analysis: A case study of a Grade 12 class in South Africa." Acta Didactica Napocenia 3(3): 36-45.

Lin, B., Y. Ko, and Y. Kuo. 2014. "Changes in pre-service teachers' algebraic misconceptions by using computer-assisted instruction." International Journal of Technology in Mathematics Education 21(3): 89-101.

Lin, Y. C., D. C. Yang, and M. N. Li. 2015. "Diagnosing students' misconceptions in number sense via a web-based two-tier test." Eurasia Journal of Mathematics, Science \& Technology Education 12(1): 41-55.

Mercer, N. and C. Sams. 2006. "Teaching children how to use language to solve maths problems." Language and Education 20(6): 507-528.

Murray, H. 2012. "Problems with word problems in mathematics." Learning and Teaching Mathematics 13: $55-58$.

Ojose, B. 2015. "Students' misconceptions in mathematics: Analysis of remedies and what research says." Ohio Journal of School Mathematics 72: 30-34.

Peng, A. 2009. Teacher knowledge of students' mathematical errors. Sweden: Umea Mathematics Education Research Centre, Umea University.

Pfeiffer, K. 2010. "The role of proof validation in students' mathematical learning." MSOR Connections 10(2): 17-21.

Polya, G. 1957. How to solve it. $2^{\text {nd }}$ Edition. Anchor Books, Garden City, New York.

Sakpakornkan, N. and T. Harries. 2003. "Pupils' processes of thinking: Learning to solve algebraic problems in England and Thailand." In Proceeding of the British society for research into learning mathematics 23: 91-97, ed. J. Williams.

Seng, L. K. 2012. "An error analysis of form 2 (grade 7) students in simplifying algebraic expressions: A descriptive study." Electronic Journal of Research in Educational Psychology 8(1): 139-162.

Sheinuk, L. C. 2010. "Intermediate phase mathematics teachers reasoning about learners' mathematical thinking." Unpublished Master of Education thesis, Wits School of Education, Johannesburg, South Africa.

Schütz, R. 2002. Vygotsky and language acquisition. http://www.sk.com.br/sk-vygot.html (Accessed 31 March 2019).

Skemp, R. R. 2006. "Relational understanding and instrumental understanding." Mathematics Teaching 12(2): 88-95.

Türkdoğan, A., M. Güler, B. Ö. Bülbül, and Ş. Danişman. 2015. "Studies about misconceptions in mathematics education in Turkey: A thematic review." Mersin University Journal of the Faculty of Education 11(2): 215-236.

Uys, M., J. van der Walt, R. van den Berg, and S. Botha. 2007. "English medium of instruction: A situation analysis." South African Journal of Education 27(1): 69-82.

Van Jaarsveld, P. 2016. "Making a case for specific language as an aspect of rigour in initial teacher education mathematics programmes." Perspectives in Education 34(1): 150-166.

Watson, A. 2010. "Developing and deepening mathematical knowledge in teaching: Being and knowing." http://www.mkit.maths-ed.org.uk/MKiT5_Watson_distribution-version.pdf.

White, A. L. 2010. "Numeracy, literacy and Newman's Error Analysis." Journal of Science and Mathematics Education in Southeast Asia 33(2): 129-148.

Yang, D. C. and Y. C. Lin. 2015. "Assessing 10- to 11-year-old children's performance and misconceptions in number sense using a four-tier diagnostic test." Educational Research 57(4): 368-388. 